\title{
LA FUNCIÓN DEL ENTENDIMIENTO AGENTE EN LA EPISTEMOLOGÍA DE FRANCISCO SUÁREZ (1548-1617)
}

\author{
Andrés Grau i Arau \\ Universitat Ramon Llull (Barcelona)
}

\section{RESUMEN}

La psicología de Suárez parte de la triple distinción aristotélica de las almas: vegetativa, sensitiva y racional. Vista la necesidad y la función de los entendimientos agente y posible en el conocimiento humano, sobre todo en el de los universales, hemos pasado a analizar sus características esenciales. El intelecto agente se presenta como una potencia no cognoscitiva limitada a la iluminación de las imágenes y a la producción de especies.

Palabras clave: Alma, Entendimiento, Especie, Suárez, Universal.

\section{ABSTRACT}

Suárez's psychology starts from the triple Aristotelian distinction of the soul: vegetative, sensitive and rational. Having appreciated the need and function of the agent and possible intellects in the human knowledge, especially in the universal ones, we have proceeded to analyse its essential characteristics. The agent intellect is presented as a noncognizant faculty limited to the lighting of images and the production of species.

Key words: Soul, Understanding, Species, Suárez, Universal.

\section{LA TEORÍA DEL ALMA EN FRANCISCO SUÁREZ}

Distinta del cuerpo, Suárez concibió el alma como el principio de la vida y el principio primero de todas las perfecciones̀ y operaciones del viviente como tal. ${ }^{1}$ «El alma --escribe- se diferencia, en primer lugar, de las formas de los seres inanimados en que produce en la materia un efecto de rango más noble, en que constituye un compuesto de mayor perfección y le confiere un ser más rico que el que confieren las otras formas. De aquí una segunda diferencia: el alma exige una materia organizada de otro modo más eminente de lo que exigen las otras formas. Ambas diferencias se pueden comprender en aquellas palabras de Aristóteles: "Es un acto del cuerpo físico orgánico"». ${ }^{2}$ La psicología suarista parte de la triple división aristotélica del alma: vegetativa, sensitiva y racional. La vegetativa, considerada como una verdadera

1 Vid. Francisco Suárez, De anima, tomo I, intr. y ed. crítica de Salvador Castellote, Madrid, Sociedad de Estudios y Publicaciones, 1978, d. 1, q. 1, pp. 63 y 67.

2 lbídem, p. 95. 
alma, es la primera y el fundamento de las otras dos; por sí misma, es suficiente para constituir un ser vivo. ${ }^{3}$ Las facultades vegetativas son tres: la nutritiva, la aumentativa y la productiva. Suárez identifica la nutrición y el crecimiento, y dice que sólo difieren por comparación con lo que se pierde. ${ }^{4}$ En cuanto a la producción o procreación, sostendrá que las plantas a veces producen frutos que llevan a un estado de perfección y a veces no. ${ }^{5}$

El ser humano posee dos facultades cognoscitivas: la sensitiva y la intelectiva. El principio sensitivo constituye la clase de seres vivientes que sienten, la cual es superior a la de los vegetales e inferior a la de los racionales. Indica el Eximio que el conocimiento sensible difiere del intelectual en el modo, es decir, en el orden de superioridad de los conocimientos, pero no en el carácter, ya que ambos son conocimiento. En los sentidos y en el intelecto, se producen, respectivamente, las especies sensibles y las inteligibles. Por el simple contacto de los sentidos externos con los objetos físicos, el cuerpo percibe inmediatamente las especies presentes en dichos objetos. Mediante los sentidos, reproducimos sensiblemente el objeto conocido. Para que se dé un conocimiento, tiene que establecerse una unión entre el sujeto que conoce y el objeto que ha de ser conocido, de lo que surgirá la especie intencional, que se define como una semejanza del objeto. La existencia de especies demuestra que la facultad cognoscitiva es determinada por el objeto conocido. Con la generación o formación de la especie, podremos ya hablar de acto del conocimiento.

El alma sensitiva precisa de un cuerpo orgánico; su acción es intrínsecamente orgánica y corporal; y signo de su perfección es tener un número considerable de órganos. ${ }^{6}$ Suárez se plantea utrum ad productionem specierum sensibilium necesse sit ponere sensum agentem. ${ }^{7}$ El problema surge al tenerse que admitir que los objetos exteriores son causa de las especies sensibles cuando ésos son materiales. Como facultades del alma, los sentidos son mucho más perfectos que los objetos materiales. Los representantes del averroísmo parecen defender que la especies sensibles no son producidas por el objeto, sino por una inteligencia espiritual suplente del objeto. ${ }^{8}$ Nuestro jesuita considera que, en los sentidos externos, las especies son producidas por los objetos, y esto lleva a mantener que no es necesario que haya en ellos un sentido agente; sin embargo, respecto al sentido interno, opina que debe necesariamente admitirse un sentido agente de especies intencionales. La razón que da el Eximio parte de la existencia de dos planos cualitativamente diferentes, pero comparables según un grado de perfección. Las especies intencionales no son más perfectas que sus objetos; asî, la blancura no es cualidad más perfecta que su especie. Suárez opina que el conocimiento sensorial se da por el efecto de una impresión material provocada por el estímulo exterior en el órgano del sentido. Esta impresión se asimila y se elabora como una semejanza intencional del objeto, como una especie sensible impresa: como huella y representación de la cualidad, pero no como la propia cualidad material. ${ }^{9}$ En cuanto a la posible existencia de un sentido agente en la formación de las especies del sentido interno, Suárez ofrece algunos argumentos aceptables, pero no concluyentes. En primer lugar, nos dirá que la especie sentida del interno no es producida por el objeto exterior mediante una especie, sino por el sentido externo gracias a su acto de conocimiento. Se dirá que

3 Vid. ibidem, d. 2, q. 1, pp. 139 y 143.

4 Ibidem, d. 2, q. 1, p. 150: Nam vivens augetur et tamdiu cessat ab actione. Id tamen provenit ex defectu, quia iam non potest tantum convertere in suam substantiam quantum amittat. Unde adhuc hoc proprie non est cessare ab operatione, nam, ut I De generatione dictum est, auctio et nutritio eadem est actio, et tantum differunt per comparationem ad id quod perditur, nam si hoc sit minus dicitur augmentatio, si maius decretio, si aequale status.

5 Vid. ibídem, p. 151.

6 Vid. ibídem, pp. 153 y 157.

7 Francisco Suárez, De anima, tomo II, Madrid, Editorial Labor, 1981, d. 6, q. 2, p. 470.

8 Vid. ibidem, p. 473.

9 Ibídem, pp. 474-476: Species istae intentionales non sunt perfectiores obiectis suis, ut albedo perfectior qualitas est quam species illius. Utraque enim est qualitas materialis, tamen albedo est perfecta in sua specie, species vero illius non est nisi tamquam quoddam vestigium et repraesentatio illius. 
el sentido interno recibe especies del sentido externo. En el sentido interno se forma una especie que representa al mismo objeto, y ello se debe a la coordinación y unión que poseen las dos facultades sensoriales en la misma alma. Tenemos, así, dos especies de categoría específicamente diferente: las externas y las internas. «La especie producida en la imaginación - comenta el Eximio- posee las mismas características que la sensación externa: cuànto más intensa es la atención del sentido externo y más rico su conocimiento a través de las especies, tanto más intensa es la impresión de las especies en el sentido interno; luego es señal de que la sensación externa es la razón de ser de la producción de la especie en el sentido interno.» ${ }^{10}$ Suárez dirá que la especie tiene que ajustarse a la facultad, y que la facultad más perfecta debe hacer uso de especies más perfectas. ¿Hay un sentido agente que genera estas especies perfectas? «La especie externa -comentará- depende del objeto, porque se produce como una participación imperfecta del mismo; pero la sensación externa, en cambio, produce la especie en el sentido interno como quien imprime en él una perfecta imagen de sí misma, que el sentido interno puede conservar muy bien de acuerdo con su disposición natural.. ${ }^{11}$

Una clase menos perfecta es separable de la más perfecta. Lo menos perfecto no incluye lo más perfecto. El alma sensitiva, constitutiva de una clase menos perfecta, es separable del alma racional, pero no sucede lo contrario. ${ }^{12}$ En los cuerpos, el principio de intelección nunca se separa del principio sensitivo. «El principio sensitivo - escribe el jesuita granadino- abstrae más de la materia y ejerce sus actos por especies intencionales y potencias superiores; a su vez, el principio sensitivo es superado por el principio de intelección porque éste opera por una potencia inmaterial sin instrumento corporal, ya que su acción es inmaterial.» ${ }^{13}$

El entendimiento es la facultad de entender de los seres humanos. La actividad cognoscitiva o intelectual en el ser humano es superior a la de los sentidos, que es lo propio de los brutos. Los actos del entendimiento o intelecto son los pensamientos o conocimientos espirituales; así, cuando el hombre aprehende las cosas, no se detiene en su mera apariencia exterior, sino que hace lo posible para llegar a su esencia. Sus operaciones, más allá de la mera percepción, son la división y la separación de las cosas; "por lo que, dejando los accidentes, indaga la noción propia de la sustancia y en ella investiga el ser y vuelve después a los accidentes, indagando la esencia propia de cada uno y el modo y orden que guardan en el sujeto.» ${ }^{14}$ Según Sergio Rábade, si se tuviera que elegir un elemento propio del sistema metafísico suarista, éste, sin duda, sería el concepto de ser. ${ }^{15}$ En resumen, los actos propios del intelecto son los pensamientos y su objeto, el ser.

Hay una cierta afinidad del entendimiento con el ser. Escribe Suárez: Objectum adaequatum intellectus nostri secundum se considerati est ens in tota latitudine sua spectatum. Patet ex praecedenti, nam objetum adaequatum ambit omnia, circa quae potest versari potentia, sed intellectus potest cognoscere quidquid habet rationem entis: id ergo erit objectum totale ipsius. ${ }^{16} \mathrm{El}$ ser es el elemento común a todo lo que puede ser conocido por el entendimiento, sea

\section{$10 \quad$ Ibídem, p. 483.}

11 Ibidem, p. 487.

12 Vid. De anima, t. I, d. 2, q. 1, p. 157. Más adelante, leemos: «También, ¿quién dirá que antes del uso de la razón el niño no siente el dolor o no ve? Nadie sin duda que sea normal, y sin embargo, el niño se comporta en ese tiempo como un bruto, pues en ninguno de sus actos usa de razón ni da más señales de conocimiento que los brutos. El mismo argumento se obtiene en el caso del hombre privado de razón. Por tanto el alma sensitiva es separable de la racional» (p. 159).

13 Ibídem, p. 157.

14 De anima, t. I, d. 2, q. 3, p. 183 (... unde, relictis accidentibus, propriam rationem substantiae quaerit, et in illa investigat quid sit de quidditate, et deinde ad accidentia revertitur, uniuscuisque propriam essentiam investigando, et modum et ordinem quem in subiecto observent (p. 182)).

15 Vid. Sergio Rábade, introducción a las Disputationes Metaphysicae (DM), Madrid, Gredos, 1960, t. 1, p. 12.

16 F. Suárez, De anima, ed. de L. Vivès, t. III, París, 1856, 1. IV, c. 1, n.3, p. 713, De anima, tomo III, Madrid, Fundación Xavier Zubiri, 1991, pp. 68-69. 
material o espiritual, sea físico o metafísico. La inmaterialidad del intelecto hace que éste llegue a conocer todo: lo creado y el Ser increado, lo posible y lo existente...; es decir, el intelecto puede conocer todo lo que se tenga como ser. ${ }^{17}$ Sin embargo, aunque el ser sea el objeto formal genérico del entendimiento, no quiere decir que sea lo exclusivamente percibido. ${ }^{18} \mathrm{La}$ disposición o capacidad del entendimiento es su inmaterialidad, tema sobre el cual Suárez no escatima palabras. El entendimiento, por su inmaterialidad, llega a conocer todos los objetos, cosa limitada por y para los sentidos, que sólo llegan a hacerlo de una clase determinada de seres. Diremos, con Clemente Fernández, que «a más inmaterialidad, mayor capacidad de conocimiento: y el puesto supremo entre todas las potencias cognoscitivas lo ocupará la que conozca más objetos, y será por tanto la más inmaterial, o más bien, su inmaterialidad será la causa de la amplitud absoluta de su objeto.» ${ }^{19}$

Podemos establecer un paralelismo entre dos triples correspondencias: (a) Sentidos-Materialidad-Objetos (cosas) / (b) Intelecto-Inmaterialidad-Ser. Según Clemente Fernández, hay en el entendimiento «una disposición, una forma que responde a esa espontaneidad en percibir el ser: brevemente podríamos decir que el ser es la forma del entendimiento.» El intelecto sólo puede conocer las cosas como ser: es «la condición necesaria de su actividad» ${ }^{20}$; aquello que no es el entendimiento tendrá que pensarlo y conocerlo incluso como ser; si ha de pensar en algo que no posee ser, tendrá que dárselo como forma. Según el Eximio, la capacidad del entendimiento es perfectiva: el hecho de dar forma o de pensar lo que no tiene ser como ser es una muestra. ${ }^{21}$

El alma racional es la forma del cuerpo; pero ello no quiere decir, como algunos pretenden, que el entendimiento sea una facultad orgánica. En la cuestión tercera de la disputa segunda del $D e$ Anima, Suárez se pregunta si el principio intelectivo humano es algo incorpóreo, subsistente e inmortal. ${ }^{22}$ Inicia la citada quaestio con la siguiente afirmación: «El conocimiento del alma intelectiva nos es tanto más difícil cuanto ella es más perfecta y más elevada sobre la materia. Por esto necesitamos para explicar su sustancia de muchos más elementos que en el caso de las otras almas, acerca de las cuales no valió la pena preguntarnos si son incorpóreas e inmortales porque ni siquiera tienen vestigio de ello.» ${ }^{23} \mathrm{El}$ intelecto es una potencia espiritual o anorgánica; y toda potencia espiritual o anorgánica, puesto que está por encima de lo material y obra independientemente de él, como es el caso de Dios y los espíritus puros, conlleva una cierta complicación para su correspondiente conocimiento. Suárez dirá que no podemos hacernos con los atributos reales y propios de la divinidad porque es un ente excelente que mantiene una distancia considerable y una mínima conveniencia con los demás entes. Para confirmar la incorporeidad y la inmortalidad del alma intelectiva, se requiere de más elementos que en las otras almas debido a su elevación sobre lo orgánico. Sin embargo, el Eximio añade una nueva pregunta: «¿Son las almas de los animales inmortales?» Suárez aporta

17 Cfr. Clemente Fernández, Metafisica del conocimiento en Suárez, Madrid, 1954, p. 72.

18. Ibídem, p. 67: «Bien que éste [el entendimiento], por su condiçón de potencia de una substancia unida intrínsecamente a la materia tenga como objeto propio la esencia de las cosas materiales: pero eso no quita que haya de conocer otros aspectos que, como los del ser, están implícitos en dicho objeto propio.»

19 Ibídem, p. 71.

20 Ibidem, p. 63.

21 Clemente Femández tiene razón cuando dice que, «en este doble valor de la ley, en la existencia necesaria en la inteligencia de una ordenación al ser, y en la consecuencia necesaria de ella, de que todo objeto inteligible se ha de conocer como ser, está en germen toda la metafísica y psicología del conocimiento humano» (ibidem, $\mathrm{p}$. 64).

22 De anima, t. I, d. 2, q. 3: Utrum principium intelligendi hominum sit aliquid incorporeum, subsistens et immortale, pp. 162-163.

23 Ibídem, p. 163 (Cognitio animae intellectivae tanto nobis difficilior est, quanto ipsa est perfectior et a materia magis elevata. Et ideo ad illius substantiam explicandam multo plura necessaria sunt quam in aliis animabus, de quibus non oportuit quaerere, an sint incorporeae et immortales, quia neque vestigium habent huius rei (p. 162)). 
argumentos de autoridad de Aristóteles, Platón, Filopón, Bessarion y Ficino, en los que se demuestra que la cuestión planteada sólo es aplicable al alma del hombre, y no deja de exponer los errores más significativos al respecto. ${ }^{24}$ De las argumentaciones favorables a la negación de la pregunta, parece simpatizar con la de Aristóteles, según la cual «todas las almas, exceptuada la humana, son materiales y mortales, porque dado que la actividad se sigue del ser, si la actividad de toda forma es material, el mismo ser será material.» 25

Por la razón natural, tendemos a afirmar que el alma es inmaterial y subsistente. Suárez, sin embargo, sostiene que esta aseveración no es demostrable a priori, puesto que no podemos comprender cómo es en sí nuestra alma; hay que demostrarlo «por actividades que experimentamos en nosotros, en el supuesto de que por el modo como es la actividad se deduce el carácter de la potencia, y de la potencia se colige la naturaleza del principio en que tal potencia radica.» ${ }^{26}$ Ya hemos dicho que el alma intelectiva es una potencia anorgánica o facultad espiritual. La naturaleza de la materia impide producir actos espirituales: es imposible que una facultad material realice un acto espiritual, como lo es que un acto espiritual tenga por sujeto una facultad corporal.

En la psicología racional suareciana, tres son los efectos de la inmaterialidad: indeterminación, universalidad e independencia. La materia limita y coarta; el espíritu, al contrario, inmaterial, es libre e indeterminado: no sujeto a límites. Cuanto más universal es la facultad cognoscitiva, más inmaterial es. El Eximio indicará que «la universalidad de la facultad pertenece eminentemente a la perfección de la misma. Luego la facultad universalísima y que puede conocer todas las cosas será simplemente inmaterial porque el «simplemente» se corresponde con el «simplemente» como el más con el más; pero nuestro entendimiento es facultad universalísima y nada se escapa a su conocimiento, luego es facultad simplemente espiritual.» ${ }^{27}$ Según Suárez, es evidente que, si desarrollamos alguna actividad espiritual y no producida por algún órgano del cuerpo, la facultad de esa actividad ha de ser también espiritual o, lo que es lo mismo, sin base en el cuerpo como instrumento de su actividad. Se confirma así la independencia del intelecto de la realidad material. Para conocer, las facultades materiales necesitan estar desprovistas de la naturaleza de sus objetos; de lo contrario, no recibiríamos las impresiones de ellos correctamente. Esto no pasa con la facultad espiritual, la cual, por el hecho de ser más elevada y no tener roce con el mundo material, tiene de por sí, sin ningún tipo de impedimento, el principio del conocimiento. ${ }^{28}$ El entendimiento posee y conserva el concepto universal, base de nuestro pensar, sin el que la inteligencia no podría ejercitarse; sin embargo, el alma necesita de la materia como condición o apoyo para producir sus intelecciones. Esta condición se ha venido definiendo, en términos escolásticos, como una dependencia extrínseca. Así, sin dejar de tener su independencia intrínseca, ${ }^{29}$ el intelecto mantiene una dependencia extrínseca con el organismo, con el cuerpo.

Tres nociones fundamentales entran en juego: operatio animae, potentia spiritualis y principium substantiale. La actividad del alma (operatio animae) sigue a la facultad espiritual (po-

24 Vid. ibidem, pp. 164-169.

25 Ibídem., p. 165 (An animae brutorum sint immortales. Qua ratione concludit Aristóteles, 2 De generatione animalium, cap. 3, omnes animas, excepta humana, esse materiales et mortales, quia, cum operatio sequatur esse, si operatio omnis formae est materialis, ipsum esse erit materiale.(p. 164)).

26 Ibidem, p. 169.

27 Ibidem, p. 179 (Rursus: ergo potentia cognoscitiva quo universalior est, eo [erit] immaterialior, nam universalitas potentiae maxime pertinet ad perfectionem illius. Rursus: ergo potentia universalissima, et quae omnia potest cognoscere, erit simpliciter immaterialis, nam sicut se habet simpliciter, ita magis ad magis; intelellectus autem noster est universalissima potentia, et nihil subterfugit cognitionem illius; est ergo potentia simpliciter spiritualis (p. 178)).

28 Vid. ibídem, pp. 176-177.

29 Nuestro autor dirá que «una virtud espiritual y un principio material no se concilian» (ibídem, p.170 (virtus autem spiritualis et principium materiale non conveniunt (p. 169)). 
tentia spiritualis) y ésta al principio substancial (principium substantiale). Si las actividades del alma son espirituales, también tendrá que serlo la facultad espiritual. Según Suárez, dicha facultad no puede tener un sujeto receptor diferente o desproporcionado a su naturaleza; de ahí que tenga que ser espiritual, es decir, no material. Si la facultad espiritual es inmaterial, también tendrá que serlo el principio substancial.

El Eximio insiste en el hecho de confirmar la incorporeidad, subsistencia e inmortalidad del alma intelectiva a partir de su inmaterialidad. Dirá que la facultad cognoscitiva postula cierta inmaterialidad. La experiencia demuestra que hay una relación directa entre inmaterialidad y facultad cognoscitiva: «Los sentidos exteriores, que son los ínfimos entre las facultades cognoscitivas, son de algún modo inmateriales y se inmutan por efecto de especies intencionales, y el más perfecto entre ellos, cual es la vista, es más inmaterial.» ${ }^{30}$ Conclusión: «cuanto más perfecta y más cognoscitiva sea la facultad, tanto será más inmaterial.» ${ }^{31}$

Los sentidos pierden su vigor con los años, mientras que el entendimiento se mantiene. Escribe Suárez: «La facultad orgánica en su aplicación al objeto por sí misma se va desgastando y encogiendo. No ocurre así con el entendimiento; sólo accidentalmente puede sentirse entorpecido a causa de una afección cerebral o de una lesión de la fantasía.» ${ }^{32}$ La intelectualidad es la máxima liberación de la materia o la forma más clara de inmaterialidad; la identificamos con el grado supremo de la vida, que es el nivel de la inmortalidad. Suárez presenta un número considerable de citas extraídas de la Sagrada Escritura, de los Santos Padres y de los concilios que prueban que, según la doctrina de la fe católica, nuestra alma es inmortal ${ }^{33}$; pero la demostración racional es lo que más le importa. Insiste en la naturaleza de la acción: entender es una actividad independiente del cuerpo, es decir, una actividad no realizada a través de una potencia corporal y orgánica; luego esa actividad sólo podrá ser espiritual. La potencia intelectiva del alma será inmaterial y, por lo tanto, también lo será la propia alma. Espiritualidad e inmortalidad son aspectos hermanados entre sí, de manera que, si se conoce la naturaleza del primero, es imposible desconocer la del segundo. Si se acepta, pues, que el alma es inmaterial, sería ridículo (ridiculum est) decir que no es inmortal. ${ }^{34}$

Suárez insistirá en la necesidad de la existencia de una estrecha coordinación de las diversas facultades de las almas y de las almas entre sí. En su ordenación psicológica, pesa más la coordinación que la graduación, a pesar de tener como importante la separación de las cosas por el grado de perfección.

\section{INTELECTO AGENTE E INTELECTO POSIBLE EN EL CONOCIMIENTO DE LOS UNIVERSALES}

Según Juan Roig Gironella, al presentar Francisco Suárez la metafísica como «un todo orgánico y sistemático», permitió que se consolidara y difundiera en el mundo moderno, y que se presentara como un «sistema coherente y abierto a sucesivos progresos». El comentario tradicional de la Metafísica de Aristóteles dejaba de tener importancia o ya estaba en crisis. El exponer esta disciplina no como una explicación capitular de la obra del Estagirita ayuda a hacer efectivo ese adelanto. ${ }^{35}$ Por otra parte, parece ser que el Eximio veía necesario, antes de entrar

30 Ibídem, p. 177 (... sensus exteriores, qui infimi inter potentias cognoscitivas sunt, [sunt] aliquo modo immateriales, et per species intentionales immutantur, et qui inter illos est perfectior, ut visus, est magis immaterialis (p. 176)).

31 Ibídem.

32 Ibídem, ps. 246-247.

33 Vid. ibidem, pp. 234-239.

34 Vid. ibídem, pp. 222-223.

35 Cfr. Juan Roig Gironella, Investigaciones metafisicas, Barcelona, Editorial Atlántida S.A., 1948 , p. 125. Cfr. también Sergio Rábade, introducción a las $D M$, p. 9. 
en materia teológica, ordenar y fundamentar los conceptos metafísicos. Al establecer en el $\mathrm{De}$ anima los lugares de las ciencias, coloca la metafísica, llamada teología natural, sabiduría y filosofía, en un segundo lugar, después de la teología. No sólo está por delante de las demás ciencias, «sino también del hábito de los primeros principios, por ser su objeto más divino. En efecto, llega hasta el mismo Dios y las sustancias separadas, y penetra más en la misma luz intelectual. $Y$ por eso es apetecible en sumo grado, y por el gran deleite que proporciona. Pero su utilidad para las cosas temporales es escasa; en cambio, es muy grande para conseguir la ciencia y para la Teología.» ${ }^{36}$ Pero el hecho de ser útil a la teología no implica que tenga que depender de ella. La metafísica comprenderá los principios y conceptos básicos de la filosofía en un sistema independiente de conocimiento.

En las Disputaciones metafísicas, obra de 1597, «nacida al calor de la densidad intelectual de la Salamanca del siglo XVI», como sostiene Sergio Rábade, ${ }^{37}$ el doctor granadino pone orden a todos aquellos temas introducidos por Aristóteles y a los comentarios que sobre éstos realizaron autores posteriores. El criterio principal de esta ordenación es la determinación del objeto adecuado de la metafísica: el ente en cuanto ente real..$^{38} \mathrm{Y}$ este objeto comprende a Dios, a las substancias inmateriales y a los accidentes reales; se excluyen los entes de razón y los que son totalmente por accidente. ${ }^{39}$ Roig Gironella divide el edificio «herreriano» de las Disputaciones en tres grandes partes: (1) introducción, (2) el tratado del ente real y (3) el tratado del ente de razón. De la parte dedicada al ente real, objeto, como acabamos de anunciar, de la metafísica, podemos establecer dos secciones: (1) la dedicada al ente trascendental y (2) la destinada a las divisiones del ente. La primera de las dos secciones se puede dividir en tres partes: (1) la que trata del concepto de ente y de su analogía; (2) la que versa sobre sus atributos y primeros principios; y (3) la relativa a las causas. En el marco de la escolástica hispana renacentista, el sistema metafísico suareciano se coloca en la línea de la filosofía aristotélico-tomista. A pesar de ser uno de los exponentes de la Contrarreforma, ejerció una notable influencia en las universidades protestantes, especialmente en las de la Alemania luterana, donde llegó a desbancar la nada desdeñable obra del reformador y humanista Philipp Melanchton (14971560).

Las psicologías de origen aristotélico defienden que las facultades intelectivas se reducen todas al entendimiento. Éste es doble: agente y posible. Al referirse a las clases formal y universal de la unidad, en la parte correspondiente a los atributos del ente en particular, Suárez se plantea la función de los dos entendimientos. En la sección sexta de la disputación primera, el Doctor Eximio se pregunta cómo hay que entender que el ser humano desea naturalmente la ciencia con apetito elícito, es decir, según un acto en grado sumo natural de la voluntad. Este apetito se llama natural por dos motivos: (a) «porque es muy conforme con la naturaleza humana y con la natural inclinación del hombre en cuanto hombre», y (b) «porque es de algún modo necesario en cuanto a su especificación.» ${ }^{40}$ Es muy común encontrar a un hombre que sacrifique una determinada ciencia por dedicarse a otra específicamente; sin embargo, esto no supone la negación de la tendencia natural al conocimiento: «apartados los impedimentos o lo que es igual - si una de ellas no fuese obstáculo para la otra, apeteceríamos naturalmente todas las ciencias y no renunciaríamos a una por causa de la otra.»41

36 De anima, t. I, prooemium, p. 41.

37 Sergio Rábade, introducción a las $D M, \mathrm{I}, \mathrm{p} .15$.

$38 D M$, I, p. 230: Dicendum est ergo ens in quantum ens reale esse obiectum adaequatum huius scientiae.

39 Ibidem: Ostensum est enim obiectum adaequatum huius scientiae debere comprendere Deum et alias substantias, sed etiam accidentia realia, non tamen entia rationis et omnino per accidens; sed huiusmodi obiectum nu-llum aliud esse potest praeter ens ut sic; ergo illud est obiectum adaequatum. Cfr. Roig Gironella, op.cit., p. 129.

$40 \quad$ Ibidem, p. 339.

41 Ibídem, p. 340: per se tamen ac seclusis impedimentis, vel (quod idem est) si una alteram non impediret, omnes scientias naturaliter appeteremus, nec ratione unius alteram despiceremus. 
¿Cómo habría que entender ese deseo si se tuviera como gravitación natural? Esta gravitación estaría dirigida hacia la ciencia misma y se identificaría con el «mismo entendimiento y su capacidad por la que mira a la ciencia como a su perfección propia.» ${ }^{42}$ Suárez no desestima enlazar, en una misma operación hacia la ciencia, el apetito elícito y la natural gravitación: «Pero si se considera la natural gravitación orientada hacia la ciencia por medio del apetito elícito, entonces no es otra cosa que la voluntad humana, que está del mismo modo naturalmente orientada hacia todas las perfecciones del hombre; porque la voluntad no apetece tener la ciencia, sino que apetece naturalmente querer la ciencia para el hombre o para su entendimiento, y en este sentido decimos que esta gravitación de la voluntad se orienta a la ciencia por medio del acto elícito.» ${ }^{43}$ Confirmar esa orientación de la voluntad hacia la ciencia, es decir, velle scientiam homini seu intellectui, requiere demostrar que la actividad intelectual sobrepasa el conocimiento sensitivo y que el conocimiento de los brutos carece de algunas propiedades del entendimiento humano. El camino hacia esa perfección que supone ser la actividad intelectual sigue unos pasos ordenados: los sentidos, la memoria, la experiencia, el arte, la ciencia y, finalmente, la sabiduría. ${ }^{44}$ El límite, ciertamente conflictivo, entre el conocimiento del bruto y el del hombre se encuentra en la experiencia; de ahí que Suárez insista en la necesidad de definirla desde los esquemas cognoscitivos del bruto y del hombre. En el animal, la experiencia es una zona pantanosa, que cuesta de determinar universalmente, mientras que en el hombre es un etapa necesaria, pero a superar por el arte y la ciencia; la experiencia, que supondría calificar algunas especies de más perfectas que otras en el género de los brutos, en el hombre sería negarse a seguir la línea hacia el estado de perfección.

Nos interesa aquí ver, en primer lugar, la funcionalidad de los intelectos agente y posible en el proceso que va desde el conocimiento del singular al del universal. El entendimiento, en la epistemología de Suárez, conoce lo singular. El primer contenido del entendimiento muestra la forma de un singular y no de un universal: lo conocido no es una noción abstracta, sino un individuo. Conocemos a Pedro o a Pablo, pero no al hombre abstractamente. ${ }^{45}$ Mediante los sentidos accede al objeto particular, que compara posteriormente con otros y que, atendiendo a su semejanza, lo piensa luego como ser y forma seguidamente el concepto universal. Desprendido de las notas particulares, este concepto sólo muestra lo que hay de común entre los objetos comparados. Al ser el entendimiento una potencia superior y más universal que la sensitiva, como ya hemos señalado en la primera parte de este estudio, el singular material entra como objeto suyo por su propia especie representativa. En este sentido, decimos que la acción del intelecto es mejor que la de los sentidos: conoce la cosa singular material por una especie propia y representativa, en la que puede ver la naturaleza de las cosas singulares, prescindiendo de las notas peculiares del individuo. Suárez nos habla en el De anima de dos tipos de abstracción: la referida a la especie y la referida a la naturaleza representada en la especie. ${ }^{46}$ Una de las novedades que introduce en materia abstractiva es atribuir al intelecto agente el primer tipo de abstracción y al posible, el segundo. Ambas abstracciones habían sido consideradas pro-

42 Ibídem:... et sic non est aliud quam intellectus ipse et capacitas eius, qua scientiam recipit ut propriam perfectionem. La analogía no es de desmerecer: Sicut enim in materia prima appetitus ad formam non est aliud ab ipsa materia, et naturali eilus capacitate, et similiter in omni alia potentia appetitus ad suum actum non est aliquid additum ipsi potentiae, sed naturalis constitutio et aptitudo ita in intellectu se habet appetitus ad scientiam (ibidem).

43 lbidem: At si consideretur pondus naturae ut terminatur ad scientiam medio appetitu elicito, non est aliud quam voluntas hominis, quae hoc modo naturaliter propensa est ad omnes hominis perfectiones; non enim appetit voluntas habere scientiam, appetit tamen naturaliter velle scientiam homini seu intellectui: et hoc modo dicimus hoc pondus voluntatis terminari ad scientiam medio actu elicito.

44 Cfr. ibidem, p. 341.

45 Cfr. Clemente Fernández, op. cit., p. 78.

46 De anima, 1. IV, c. 3, n. 19, p. 728: Quarta dubitatio ex superioribus quoque ita resolvenda constat nimirum ex dictis abstractionem, vel posse referri ad speciem ipsam, vel ad naturam repraesentantem in specie. 
pias del intelecto agente; sin embargo, Suárez cree que éste no tiene como función la abstracción de la naturaleza universal. El entendimiento agente, como muy bien afirmará José $\mathrm{M}^{\mathrm{a}} \mathrm{Ale}$ jandro, «sencillamente no universaliza. ${ }^{47}$ Por exclusión y por necesidad, la tarea tendrá que recaer en el entendimiento posible. ${ }^{48}$ Apunta Eleuterio Elorduy que Suárez distingue dos procesos distintos: (1) la formación de la especie inteligible mediante la abstracción que alguna vez llama entitativa; (2) la abstracción de la naturaleza universal de las condiciones individuantes con que es conocida en dicha intelección directa, una vez que el entendimiento posible fecundado por la especie inteligible produce la intelección o concepto formal. ${ }^{49} \mathrm{Al}$ universal se llega por operaciones diferentes y diferenciales que describen el nivel más elevado del proceso cognoscitivo humano. La tarea del intelecto agente es producir las especies inteligibles en el posible, y en ello la agota. Atribuirle la abstracción de una naturaleza universal supondría, en cierta manera, verlo como una potencia cognoscente, cosa que, en la epistemología de Suárez, no parece contemplarse. «La naturaleza así descortezada de sus caracteres individuales sostiene Elorduy-, mediante conocimientos posteriores, será la naturaleza universal.» ${ }^{50} \mathrm{El}$ universal se ha de hallar en las cosas constituyendo una unidad formal que permita al entendimiento realizar la abstracción. La especie de «Pedro» no.puede representar a este hombre sin hacerlo del hombre. Por esa especie, se puede conocer, y, por ello, es superflua otra especie. ${ }^{51}$ El entendimiento posible no necesita otro complemento objetivo para conocer el singular: le basta la misma especie impresa. Según Clemente Fernández, «el conocimiento singular suareciano no es un conocimiento desprovisto de todo elemento universal, sino que es un universal terminado a un singular.» El sentido del conocimiento del singular de Suárez es que «antes se conoce al hombre como terminado y poseído por Pedro, que el hombre abstracto y separado de todo individuo; pero aun entonces se le conoce ya, aunque afectado del índice de singularidad (homo, ut in Petro)..$^{52}$

Tres tipos de universal hallamos en la teoría suarista del conocimiento: (a) el metafísico: «anterior a la realidad», (b) el físico: «en la realidad» y (c) el logico: «posterior a la realidad». ${ }^{53}$ La universalidad metafísica es aquella que la tiene por extrínseca denominación y abstracción del intelecto; por ella, la naturaleza es representada como común e indiferente. Sin embargo, no hay un universal metafísico propiamente dicho: sería algo independiente de los individuos que abstraería en grado máximo de toda mutación y contracción; su única distinción posible no es realmente, sino por la razón. El universal físico es la misma naturaleza universal que se encuentra en las cosas; por ello, no se puede considerar formalmente, sino sólo materialmente, es decir, como naturaleza abstraída. Al hallarse en las cosas, está sujeto al cambio y a los accidentes del mundo sensible. En el libro cuarto del De anima, Suárez nos dirá que las apelaciones de este tipo no son totalmente necesarias: la universalidad física podrá perfectamente decirse metafísica, ya que no es más que la abstracción de la materia realizada por un me-

47 José Ma Alejandro, «Esencia y valor del conocimiento según el Doctor Eximio», Miscelánea Comillas, 9 , Santander, 1948, p. 240.

48 De anima, 1. IV, p. 728: si ad speciem referatur, operatio est intellectus agentis, qui abstrahere dicitur species a phantasmatibus propter rationem in praecedentibus allatam: si vero referatur ad naturam repraesentatam, communiter etiam asseritur hujusmodi abstractionem fieri virtute intellectus agentis producentis speciem repraesentantem nudam per universalis naturam. Ea ergo abstractio oeratio est intellectus possibilis, qua naturam universalem considerat absque conditionibus individuantibus, sic enim per actum illum repraesentatur natura, ut universalis, atque abstracta. De anima, t. III, d. 9, q. 3, pp. 136-137.Cfr. Eleuterio Elorduy, «El concepto objetivo en Suárez», Pensamiento, vol. 4, 1948, pp. 369-370.

49 Vid. Eleuterio Elorduy, op. cit., p. 370.

50 Ibidem.

51 Cfr. De anima, 1. IV, c. 3, n. 12; De anima, t. III, d. 9, q. 3, pp. 124-125.

52 Clemente Fernández, op. cit., p. 104.

$53 D M, \mathrm{I}$, p. 772: Hinc secundo dividi solet universale in universale metaphysicum, physicum ac logicum, quae aliis nominibus dici possunt universale ante rem, in re et post rem. 
tafísico; y la metafísica podrá calificarse de física porque difícilmente el físico puede discernir las operaciones del intelecto sin abstracciones. ${ }^{54}$ Por último, el universal lógico es el mismo universal en acto que resulta de la operación del entendimiento. Se puede tener como la segunda universalidad aplicada a la naturaleza, es decir, como algo que estuviera en ella. Estudiado por el dialéctico, Suárez, no obstante, opina que es más propio del metafísico, ya que a él le corresponde la investigación de los entes de razón. ${ }^{55}$

En la sección sexta de la disputación VI, Suárez se pregunta por la operación del entendimiento que universaliza las cosas. El Eximio destaca que esta cuestión se plantea también en la dialéctica y en el De anima, lugar este último en el que cree más apropiado que se trate. Deja claro, quizás por lo que han supuesto las reformas de la lógica renacentista, que lo que se refiere al intelecto y a su objeto no es materia propia del arte de razonar, sino de la ciencia del alma. El dialéctico sólo se cuestiona si el universal se obtiene por abstracción o por una comparación del intelecto. ${ }^{56} \mathrm{La}$ unidad universal es el resultado de una operación del entendimiento; por ello, no podemos pasar por alto explicar cuál es esta operación del entendimiento ni sus características; y lo primero que se tiene que hacer es distinguir los dos entendimientos: el agente y el posible. ${ }^{57} \mathrm{La}$ función del agente, dirá el Doctor Eximio, es producir las especies inteligibles; la del posible, actuar y realizar la intelección mediante esas especies. ${ }^{58}$ Atribuye al intelecto posible dos operaciones: (a) directa: por la que tiende directamente al objeto que la especie inteligible representa y hacia el que dirige esencial y absolutamente al entendimiento; y (b) refleja: por la que el entendimiento vuelve sobre el conocimiento anterior o sobre el objeto de éste, según las condiciones o denominaciones que recibe el conocimiento. ${ }^{59}$

Suárez aborda el tema con la exposición de tres opiniones: (a) lo universal se produce por la operación del entendimiento agente; (b) lo universal es producido por el entendimiento posible; y (c) lo universal se obtiene por un conocimiento comparativo.

Según la primera opinión, se da una natural primacía del intelecto agente, considerado el más elevado, sobre el posible. La operación del intelecto agente antecede a todo acto del entendimiento posible. El entendimiento agente produce una especie inteligible, la cual representa la naturaleza precisa y abstraída de una serie de individuos, y es universal y común objetivamente en la representación. Por su parte, el entendimiento posible, en clara dependencia del agente, sólo conoce las naturalezas comunes y se le veta un conocimiento directo de los singulares materiales. El universal es el objeto del entendimiento agente y posible: del primero como potencia activa; del segundo, como pasiva o receptiva; un entendimiento produce las especies inteligibles y otro realiza la intelección por ellas. ${ }^{60}$

La segunda opinión es defendida por aquellos que opinan que el entendimiento posible conoce directamente no sólo los singulares, sino también las cosas materiales. Parte del hecho que lo universal es producido por el entendimiento posible mediante una operación directa e inmediata que le permite conocer la naturaleza común específica según su razón precisa formal y según su esencia. El universal es el género y no se obtiene por la abstracción del entendi-

54 Vid. De anima, 1. IV, c. 3, n. 22, p. 729. De anima, t. III, d. 9, q. 3, pp. 142-145.

55 Ibídem, pp. 772-773. Cfr. De anima 1. IV, p. 729. De anima, t. III, d. 9, q. 3, pp.142-143.

$56 D M, \mathrm{I}$, p. 751: Haec quaestio sub aliis verbis tractari solet in principio dialecticae, scilicet, an universale fiat per abstractionem vel per comparationem intellectus. Tractari etiam solet, ac magis proprie in III de Anima, explicando obiectum intellectus, quod universales esse dicitur.

57 Ibídem: Oportet autem breviter distingere duplicem intellectum, agentem et possibilem.

58 Ibidem: Illius munus est efficere species intelligibles; huius operari et intelligere per illas; habet autem duplicem operationem (praetermissis aliis quae ad praesens institutum non spectant).

59 Ibidem: Una vocatur directa, qua directe tendit in rem quam species intelligibilis repraesentat et ad quam ducit intellectum per se ac simpliciter. Alia vocatur reflexa, qua intellectus revolvitur supra priorem cognitionem vel supra obiectum eius secundum eas conditiones o denominationes quas ex cognitione accipit.

60 Vid. ibidem, pp. 751-752. 
miento agente, el cual abstraerá sólo la especie inteligible del fantasma por separarla de las condiciones de la materia en cuanto al ser real de la misma, pero no en cuanto al objeto que representa. $^{61}$

En la tercera opinión, lo universal, entendido como un ente o relación de razón, se obtiene por un conocimiento comparativo y es actividad del entendimiento posible. Se trata de una segunda intención formal y la naturaleza que conocemos la definimos como una segunda intención objetiva. ${ }^{62}$ Se parte de una aprehensión precisa y abstracta de la naturaleza de las cosas singulares, la cual tiene universalidad sólo en potencia remota, ya que no se presenta como algo verdaderamente uno que existe en una multitud. Luego se comparará ésta así concebida con las cosas en que existe, y la concebirá como algo apto para existir en muchos inferiores y predicarse de ellos. El universal sólo posee ser objetivo en el entendimiento y sólo existe en virtud del conocimiento comparativo. ${ }^{63}$

Es en el análisis u objeción de la primera opinión donde podemos observar, no sin dificultad, la operatividad de ambos intelectos en relación a los universales. Suárez propone condiciones para aceptar dicha opinión, la cual, por las principales fuentes expuestas, se puede enmarcar en la tradición tomista. Para los seguidores de esta tendencia escolástica, el entendimiento, por su naturaleza, únicamente conoce lo universal; así, después de haber conocido lo material a través de los sentidos, el intelecto constituye inmediatamente un concepto universal. Para nuestro jesuita, el entendimiento agente no produce las especies representativas de los individuos ni tiene valor general para toda universalidad, sino para la específica y sólo formalmente hablando. ${ }^{64}$ Suárez parte de la limitación del intelecto agente. Cuando afirma que no produce las especies representativas de los individuos, quiere decir que no imprime nunca una especie representativa de la diferencia como tal. Su misión es imprimir toda la naturaleza común o específica.

La especie, en general, puede entenderse como una representación del objeto. Es impresa o expresa. Siguiendo al de Aquino, Suárez dirá que el entendimiento agente es el que produce la especie impresa a partir de la reproducción sensible del objeto. «Los objetos externos - escribe Eleuterio Elorduy - son el primer estímulo que determina en los sentidos y en la inteligencia esas energías, que llamamos especies.» ${ }^{65}$ Éstas son el origen del conocimiento que el entendimiento pasivo consigue cuando retiene la representación de un objeto en una producción mental. Este producto mental es la especie expresa o, si se prefiere, el verbo mental, pues, en esta especie, el entendimiento expresa el objeto captado. Leemos en el De anima: «La dicción (verbum) ni es la especie impresa ni algo distinto del acto intelectivo. Es por consiguiente el acto mismo.» ${ }^{66} \mathrm{El}$ verbum mentis es el acto cognoscitivo $\mathrm{y}$, por lo tanto, no se distingue de la intelección misma.$^{67}$ «No es el lugar en el que se realiza el conocimiento, ni hace las veces del objeto - matiza el Eximio-; es aquello por lo que el objeto es conocido a manera de concepto formal de la cosa conocida». ${ }^{68} \mathrm{La}$ distinción es simplemente modal. Para poder entender una cosa es necesario que ésta se realice en el entendimiento, y esta realización

61 Vid. ibidem, pp. 752-755.

62 De anima, 1. IV, c. 3, n. 21, p. 729: Atque haec vocatur notitia comparativa, seu secunda intentio formalis: natura vero, ut sic, cognita, appellatur secunda intentio objetiva. De anima, t. III, d. 9, q. 3, pp.142-143.

63 Vid. $D M$, I, pp. 755-756.

64 Ibidem, p. 757: Inter has sentencias prima est quidem probalis ex suppositione illius sententiae, quod intellectus agens non producit species repraesentantes individua, et adhuc ea supposita, non procedit generaliter de omni universali sed ad summum de specifico et de solo illo formaliter loquendo,...

65 Eleuterio Elorduy, op. cit., p. 359.

66 De anima, t. II, d. 5, q. 5, p. 387.

67 Ibídem, p. 386: Probavimus enim per actum cognoscendi non produci aliquid ab [ipso]distinctum, et tamen producitur verbum; ergo verbum non est aliquid distinctum ab actu [cognoscendi].

68 Ibidem, p. 388: Quod non est id in quo fit cognitio, neque supplet vicem obiecti, sed est id quo ipsum obiectum cognoscitur, tamquam conceptu formali rei cognitae. 
es el verbo mental. La dicción será, pues, no el concepto objetivo de la mente o cosa conoci$\mathrm{da}$, sino el concepto formal..$^{69}$ Suárez define este concepto como primera intención, y la naturaleza universal o concepto objetivo, como primera intención objetiva. ${ }^{70}$

El intelecto agente no es libre en el obrar: imprime la especie de acuerdo con su naturaleza, supuesto el fantasma representativo. No es tampoco cognoscitivo: no puede concebir la naturaleza de una manera ahora y luego de otra. El entendimiento agente, según hemos anunciado anteriormente, sólo abstrae la naturaleza específica. «La especie impresa —explica el Doctor Eximio - ni es imagen formal, ni en modo alguno representa formalmente sino eficientemente, en cuanto es como el germen o instrumento del objeto para efectuar la representación formal intencional que se realiza por el concepto de la mente.» ${ }^{71}$ Por esta representación, el objeto se hace presente en el alma racional. Su naturaleza no está representada propiamente en la especie impresa, sino sólo de manera remota y mediata (remote et mediate). Insiste Suárez en que esa especie es la que realiza el acto al que aquella naturaleza se presenta objetivamente. Si aceptamos que el universal se produce por la abstracción del entendimiento agente, esto sólo se puede entender en hábito. De esta manera, la especie impresa no abstrae de la representación del individuo que representa en la imagen o fantasma, sino de la propia imagen, considerada en su materialidad real y entitativa. El elemento que representa la especie producida por el intelecto agente es el mismo que el del fantasma. La diferencia radica en que el fantasma es una representación material y la especie, en cambio, es espiritual. La abstracción del intelecto agente en Suárez, según Clemente Fernández, es la producción de una especie de entidad no material, pero no en su representación, la cual, como el fantasma, sigue representando lo material e individual. ${ }^{72}$ Fantasma y especie representan el mismo objeto material, pero no de la misma manera. La distinción está marcada por la naturaleza de la facultad reproductora. Así, la fantasía lo hace como un mero agregado de cualidades sensibles, mientras que el intelecto agente lo hace como ser. El entendimiento agente, cuando entra en contacto con el objeto, que es representado en la imagen de lo material, ya se hace con el elemento ontológico subyacente. Lo que producirá en el entendimiento posible se presentará como ser y se especificará en un universal; ahora bien, puesto que la especie impresa representa lo singular, el universal que se especifique tendrá que contener ese singular. ${ }^{73}$ Lo representado - y aquí vemos la novedad suareciana - aunque contenga la singularidad y la universalidad, las supera en una síntesis final ${ }^{74}$ en la que no se deja de mostrar, al menos en el orden temporal, la prioridad del conocimiento singular sobre el universal.

Suárez, sin embargo, añadirá que, sin la materialidad real y entitativa del fantasma, puede darse la representación de dicho individuo; ciertamente, esta representación se puede realizar mediante una forma o una entidad espiritual, como pasa en los ángeles o en el mismo Dios. «El entendimiento agente - señala Eleuterio Elorduy - se vale ordinariamente de asociaciones de imágenes rememorativas para producir especies impresas inteligibles con las cuales desarrolle la mente su actividad propia.» ${ }^{75}$ No hay, pues, ninguna razón física que impida la producción de la especie por parte del entendimiento agente. Este ha sido otorgado para que, mediante su operación espiritual intermedia, convierta al entendimiento posible, si puede, en semejante

69 Vid. ibídem, p. 389.

70 De anima, 1. IV, c. 3, n. 21, p. 728: Primum realiter datur in natura ipsa est natura, cognosciturque ab intelectu directa cognitione, quae solet dici prima intentio, seu conceptus formalis: natura vero sic cognita prima intentio objetiva, sive objectivus conceptus. De anima, t. III, d. 9, q. 3, pp. 140-141.

$71 \quad D M, \mathrm{I}, \mathrm{pp} .758$.

72 Clemente Fernández, op. cit., p. 77.

73 Cfr. ibidem., p. 78.

74 «El contenido presenta — escribe Clemente Fernández - la forma o esquema, no de <ser>, o de <este> simplemente, sino de <este ser>» (ibídem).

75 Eleuterio Elorduy, op. cit., p. 366. 
a la representación del fantasma. Suárez concluirá que el intelecto agente no realiza necesariamente la abstracción de lo universal; e incluso se puede llegar a decir que, quizás, no se pueda realizar de ningún modo, ya que, si se admite que el entendimiento agente es causa efectiva de las especies de las cosas singulares, es creíble que nunca se puedan producir especies representativas de naturalezas abstraídas de los singulares. ${ }^{76}$

\section{LA NATURALEZA DE LOS INTELECTOS EN EL DE ANIMA}

Obra póstuma, el De anima (1621) nos llega retocado por el P. Baltasar Alvares. «No se olvide —escribe Sergio Rábade - que en la mente de Suárez esta obra se encuentra en el mismo plano que las Disputaciones metafisicas; si en éstas están ausentes los problemas psicológicos, es precisamente porque a ellos estaba reservado el tratado De anima.» ${ }^{77}$ Como con las Disputaciones Metafísicas, Suárez pretende que su tratado De anima sea una superación de los comentarios a la obra del Estagirita y se presente como el curso de una ciencia original. ${ }^{78}$ Sin dejar de recordar que la teología destaca en efectividad y bondad sobre las demás ciencias para alcanzar los bienes de la voluntad, admite que la parte de la psicología que demuestra la inmortalidad y la nobleza del alma tiene un lugar privilegiado para conseguir dicho fin, elevando el espíritu a ideales más altos. ${ }^{79} \mathrm{La}$ ciencia del alma «trata de los actos del entendimiento, su luz, y su objeto.» Como la metafísica, Suárez cree que esa ciencia es de gran utilidad para el resto, ya que «enseña que el entendimiento realiza una reflexión perfecta sobre su acto y sobre la luz de que dispone. $\gg^{80}$ Gracias a esta ciencia, el hombre, ser dotado de entendimiento, llega a conocerse a sí mismo. ${ }^{81}$

Tomás de Aquino sostuvo que tanto el intelecto agente como el posible eran potencias del alma y no substancias separadas del cuerpo.$^{82}$ En la psicología suareciana, intelecto agente e intelecto pasivo son una y la misma facultad del alma. Si se quieren conocer perfectamente éstos, no se puede hablar de uno sin estudiar el otro ${ }^{83} \mathrm{La}$ potencia que recibe la especie y que produce el acto de entender se conoce como intelecto posible. Por las especies recibidas, este intelecto conoce. Se puede tener como la facultad que percibe las cosas inteligibles. Al entender, el intelecto pasivo se perfecciona. Pero para que dichas especies se conviertan en inteligibles, se precisa de la intervención del entendimiento agente. El entendimiento agente es la fuerza o potencia activa que produce las especies o que, si se prefiere, abstrae las especies inteligibles de las sensibles; su función no es recibir, sino sólo hacer. Se llama intelecto no porque conozca, sino porque produce cosas inteligibles. ${ }^{84}$ Suárez destaca la existencia de dos particularidades del intelecto paciente que no se dan en el agente: la función cognoscitiva o receptora de les especies, y la posesión de una acción vital, al ser acción de conocer. La acción del intelecto posible se rige por un principio intrínseco activo, cosa que no sucede en el intelecto agente; de ahí que se diga que la acción del intelecto posible sea immanens y la del agente transiens. ${ }^{85}$

Cfr. $D M, 1$, pp. $758-759$.

lbídem, p. 8.

Cfr. Roig Gironella, op.cit., p. 125.

Vid. De anima, t. I, prooemium, p. 39.

Ibidem, p. 47.

Cfr. ibidem, p. 49.

Vid. Tomás de Aquino, Suma Teológica, I, q. 79. 4. 5.

Cfr. De anima, 1. IV, c. 8, 1, p. 740.

Ibidem.

Ibídem, p. 741. 
Para el doctor Eximio, entendimiento y materia, como ya hemos visto, son realidades antagónicas: el primero penetra las cosas con su sutileza, separando las afecciones propias de la esencia y distinguiendo las varias formalidades existentes en una sola y la misma cosa, hecho que rivaliza contra la esencia de la materia, que confunde muchas cosas en un solo compuesto, «siendo propio del ser material el exigir composición; luego lo que tan sustancialmente penetra no es ciertamente corpóreo. Por lo cual todos los sentidos conocen las cosas tan confusamente que, junto con sus objetos propios, perciben otras muchas cosas accidentalmente, y no pueden distinguirlas y formar un concepto propio de cada una, que es lo que lleva a cabo el entendimiento.» ${ }^{86} \mathrm{La}$ calificación de «pasivo» puede prestarse a ciertos malentendidos, y más cuando la fuente a la que se recurre - en este caso el propio Aristóteles- no es clara. «Dice Aristóteles - escribe el jesuita- que el entendimiento pasivo es corruptible, y añade que después de la muerte no hay memoria en nosotros. Después de la muerte, por tanto, el alma no entiende y por ende no actúa. Luego no perdura su existencia, ni es por tanto inmortal.» ${ }^{87}$ Decir con Santo Tomás, Temistio y Filópono que el intelecto pasivo es la facultad cogitativa, entendiendo por ello algo racional, le permitirá colocarse en el terreno de la inmaterialidad. ¿Cómo entender la corrupción del intelecto pasivo de la que habla Aristóteles? Siguiendo a Simplicio, Suárez indica que, al morir el hombre, no se da una destrucción total de dicho intelecto, sino sólo de su pasividad. Si se acepta esta interpretación, se podrá avanzar que el pasivo es el entendimiento que, en el cuerpo, está en potencia y con capacidad de recibir especies; mientras que, una vez separado de él, se hallará siempre en acto y ya no permanecerá pasible. La muerte no supone el final del entendimiento, sino sólo el de uno de sus aspectos, lo cual significa, en cierta manera, una liberación. Hemos dicho que los intelectos no son facultades diferentes, sino potencias de una misma facultad. Al morir, el intelecto se libera de la imperfección de su potencia pasiva: «separado del cuerpo estará siempre en acto y por lo mismo no permanecerá pasible.» ${ }^{88} \mathrm{El}$ acto es superior a la potencia pasiva, y encontrará la ratificación del argumento en Santo Tomás: «en los ángeles no se da entendimiento posible, porque siempre están en acto; se destruye por tanto el entendimiento pasivo en lo tocante a su carácter de pasividad, no de manera absoluta.» De lo que parecía una muerte segura, pasamos a la recuperación del grado de dignidad y perfección del entendimiento en acto, y a la eliminación de las potencias, al menos la de la pasividad.

No parece haber dudas, en cambio, sobre la eternidad del entendimiento agente. De la lectura de Aristóteles, se puede interpretar más como una sustancia eterna, que se separa del cuerpo al morir éste, que como una facultad. En diversos lugares de su magna obra, Tomás de Aquino, contra el trascendentalismo de Averroes, sostuvo que el intelecto agente no era una sustancia separada, sino algo perteneciente al alma. En el libro IV del De Anima, Suárez expone las diversas opiniones de filósofos paganos sobre la separación y distinción de ambos intelectos, y la identificación del agente con la divinidad, como creía Alejandro de Afrodisia, o con la inteligencia última que preside las esferas, como opinaba Avicena. ${ }^{89}$ No niega Suárez

86 De anima, t. I, d. 2, q. 3, p. 183: Nam intellectus subtilitate sua res adeo penetrat, quod proprias passiones ab essentia separat [et] in unica et eadem re plures rationes formales distinguit. Quod est contra rationem materiae quae [multa] in uno composito confundet; et proprium est rei materialis compositionem ex multis postulare; id ergo quod tam substantialiter penetrat sane corporeum non est. Qua ratione sensus omnes ita in confuso res cog. noscunt, [ut] simul cum propriis obiectis multa alia per accidens concipiant, nec possint illa distingere et uniuscuisuque proprium conceptum formare; quod facit intellectus (p. 182)).

87 Ibídem, p. 231. Según Suárez, «este pasaje es muy difícil y depende de la manera cómo se entienda esa dificultad...» (ibídem).

88 Ibidem.

89 Vid. De anima, 1. IV, c. 8,3 p. 741: In qua re Graeci fere omnes hallucinati sunt, ponentes intellectum agentem et possibilem esse substantias separatas, concedentesque animae nostrae tantum cogitativam, quam intellectum passivum vocant. Ita Theophrastus et Themistius, lib. 3, de Anima, Alexander autem, lib. 2, inquit intellectum agentem esse Deum ipsum, ac quod saltem sit substantia aliqua ex separatis, putarunt Arabes, Avempace, et quos 
que las palabras de Aristóteles son favorables a la teoría del filósofo árabe: el intelecto agente, al ser acto de la sustancia, está falto de pasión y separable; no puede conocer a veces y a veces dejar de hacerlo; separado, es sólo aquello que en realidad es: inmortal, etc. ${ }^{90}$ La separación parece ser la condición del conocimiento en acto. Sin embargo, Suárez insiste en no dejar de ver el intelecto agente como una potencia del alma, cosa que implica haber de residir en ella y no haberse de contemplar como una inteligencia separada. Fiel a las tesis tomistas, el Eximio manifestará que Aristóteles, cuando afirmó que el intelecto agente estaba separado, quiso decir separado del órgano corpóreo. Ciertamente, al considerarse una potencia espiritual, cuando se diga que es separable, se entenderá separable totalmente del cuerpo al cual está unido. ${ }^{91}$

En el primero de los Diálogos de amor de León Hebreo (1460-1535), Filón indica que «hubo algunos sabios que estimaron que la felicidad consistía en el conocimiento de todas las ciencias de las cosas; de todas, sin que faltase ninguna.» Continúa: «Dicen que nuestro entendimiento es, en principio, pura potencia de entender, y que esa potencia no va dirigida a ninguna clase de cosas, sino que es común y universal para todas. ${ }^{92}$ La existencia de una facultad universal posibilita el conocimiento de todo y el conocimiento universal nos permite constatar la existencia de una facultad cognoscitiva universal. El judio portugués recurre al Estagirita: «Como dice Aristóteles, la naturaleza de nuestro entendimiento posibilita entender y captar cualquier cosa, como la naturaleza del entendimiento agente, que es el que hace los símiles intelectivos e ilumina con ellos nuestro entendimiento, obligándole a hacer todas las cosas intelectuales, e ilumina e imprime todas las cosas en el entendimiento posible, que en definitiva es el paso desde la oscura potencia al acto, iluminado por el entendimiento agente. ${ }^{93}$ Las funciones o actos propios del entendimiento agente se concretan aquí en dos: iluminar el fantasma sensible, separando en él la naturaleza de lo puramente individual, y perfeccionar el entendimiento pasivo. El aspecto del intelecto agente que resalta León Hebreo es el de la iluminación. Establece una correspondencia entre el iluminismo - ¿metafórico? - aristotélico y la relación potencia-acto. La potencia, vista como imperfección, se identifica con la oscuridad; el acto, superior a la potencia y entendido como perfección, con la luz. El entendimiento agente es la luz que permite la actualización de lo inteligible; de donde se deduce, según el pensador judío, «que su perfección y felicidad últimas deban consistir en la total transformación de potencia a acto de todas las cosas que existen, ya que, al estar en potencia en todas, su perfección y felicidad consistirá en conocerlas todas, de suerte que no quede en él potencia ni falta. alguna.» ${ }^{94} \mathrm{Y}$ concluye: «Ésta es la beatitud última y el feliz fin del entendimiento humano. Dicen que, en ese fin, nuestro entendimiento está privado por completo de potencia y se hace actual; y en todas las cosas se une y se convierte en intelecto agente iluminador cuando se ha eliminado la potencia que es causa de la diversidad. De este modo, el entendimiento posible se hace puro en acto, y esa unión es la perfección última y verdadera felicidad. A dicha unión se la denomina feliz copulación del entendimiento posible con el entendimiento agente. ${ }^{95}$

refert Albertus 3, de Anima, tract. 2, cap. 4, Averroes 3, de Anim., text. 5 et 20, et 12 Metaphysicae, text. 17, Avicenna, quoque 9 Metaphysicae, cap. 4, credit intelligentiam ultimam, quae praesidet sphaerae activorum et passivorum esse intelligantiam agentem, quae gubernat animas nostras, et 6, Natural., p. 5, c. 5 et 6, addit species intelligibiles esse in ea ipsa intelligentia, ex illaque derivari in easdem animas. De anima, t. III, d. 9, q. 8, pp. 214-215.

90 Ibidem: Huic sententiae favere videtur Aristoteles 3, de Anima, textu 19 et 20, ubi de intellectu agente ait, quod passione vacat, ac separabilis est, cum sit substantiae actus: et infra ait: Non quandoque intelligit, quandoque vero non intelligit, separatus vero, id est, atque id solum est immortale, etc. De anima, t. III, d. 9, q. 8, pp. $214-215$.

91 Vid. ibidem, p. 742.

92 León Hebreo, Diálogos de amor, ed. de C. Mazo del Castillo y J. M. Reyes Cano, Barcelona, PPU, 1993, p. 129.

93 Ibidem, pp. 129-130.

94 Ibidem, p. 130.

95 Ibídem, p. 130. 
La atribución exclusiva de iluminación al intelecto agente por parte de una determinada tradición, a la que, como acabamos de ver, se uniría León Hebreo, plantea una duda al Doctor Eximio: ¿sólo es luz el intelecto agente o lo es también el posible? Si se ha de ser fiel al texto de Aristóteles, sólo el intelecto agente se equipara a la luz; sin embargo, Suárez considera que lo mismo se ha de decir del posible, aunque por otra razón. La oscuridad de la exposición del texto del Estagirita es lo que incita a nuestro jesuita a no moverse del terreno de la analogía. Ese Aristoteles quidem agentem intellectum lumen vocat le permite añadir idem vero sentiendum de possibili, licet diversa ratione. ${ }^{96}$ Aunque la luz, en primer lugar, se dice de lo material y tangible, también se habría traspasado su nombre a los seres espirituales, no metafóricamente, sino propiamente. Pero más allá de las atribuciones de materialidad o espiritualidad, Suárez va -al encuentro de una definición esencial. Recurre al artículo primero de la cuestión 67 de la primera parte de la Suma Teológica de Tomás de Aquino. De las tres fuentes propuestas para demostrar utrum lux proprie in spiritualibus dicitur, la de Agustín, la de Dionisio Areopagita y la de la Carta de San Pablo a los Efesios, Suárez se queda con esta última. Escribe Santo Tomás: Apostolus dicit, ad Eph. 5,13: "Omne quod manifestatur, lumen est". Sed manifestatio, magis proprie est in espiritualibus quam in corporalibus. Ergo et lux ${ }^{97}$ El Eximio, sin embargo, acepta la definición paulina como una definición general y posteriormente la confirma con la cita bíblica: lumen proprie sit quidquid manifestativum est, justa illud ad Eph. 5: "Omnia, quae arguuntur, manifestantur a lumine". Luz, en sentido propio, es todo lo que se manifiesta; por lo tanto, manifestatio autem etiam in rebus spiritualibus proprie reperitur. ${ }^{98} \mathrm{~A}$ partir de esta definición, Suárez contempla, en primer lugar, la naturaleza lumínica del intelecto agente. Ciertamente, se le ha de decir luz porque muestra la cosa al intelecto posible, es decir, al intelecto en acto primero. El intelecto agente produce en el posible las especies de las cosas; por ello, se dice también que manifiesta e ilumina las imágenes del entendimiento posible. Su función parece reducirse a producir especies y a hacer evidentes las imágenes en el entendimiento posible. Suárez deja claro que no procede ningún otro tipo de iluminación del intelecto agente. ${ }^{99}$ Pero, centrándose en la definición aceptada de luz, advierte que cualquier objeto sensible podría decirse luz, porque, produciendo especies de él, él mismo se manifiesta a un sentido. Sin embargo, tal vez luz se dice más de los que manifiestan otras cosas que no de los que se manifiestan a sí mismos. Si esto se admite, el intelecto posible, puesto que manifiesta la verdad en las cosas y obtiene el juicio de ellas, sería también luz. ${ }^{100}$ Suárez sostiene que el intelecto se conoce a sí mismo, conoce sus actos, sus especies y su luz, y que posee capacidad discursiva y del juicio. Matizará que el entendimiento, «deduciendo conclusiones a partir de un principio, juzga de la verdad de todas las cosas.»101

Contra Teofastro, Avicena, Averroes y los averroístas, Suárez defenderá que el intelecto, agente y posible, no es uno y el mismo en todos los hombres. Para el pensador de Córdoba, entre intelecto agente y paciente, no había distinción: los dos eran uno solo, y el intelecto, además, era único y pensaba en todos los hombres. El hecho de haber ese solo entendimiento y existir fuera de las almas llevó a sostener que aquél era inmortal y que éstas eran mortales. «Ponen en el hombre - escribe el Eximio- una cierta forma sustancial que lo constituye en

96 Vid. De anima, 1. IV, c. 8, a. 9, p. 743.

97 I q. 67 a. 1 (Santo Tomás de Aquino, Suma Teológica, tomo II-III, Madrid, BAC, 1959, p. 1017.)

98 De anima, 1. IV, c. 8 , a. 9 , p. 743.

99 Ibidem: neque alia profecto illuminatio procedit ab intellectu agente, quia neque in phatasmate lumen aliquod producit, neque item medio, cum nullum tale sit, per quod cognitio intellectualis diffundatur.

100 Ibidem: Inferes: ergo etiam quodlibet objectum sensibile dici poterit lumen, quatenus producendo species sui seipsum sensui manifestat. Illatio quidem in rigore admittenda esset, si usus ferret. Fortase tamen lumen magis dicitur de his, qua alia, non quae seipsa manifestant. Deinde intellectus possibilis lumen quoddam est manifestans veritatem in rebus, et judicium ferens de illis. De anima, t. III, d. 9, q. 8, pp. 228-229.

101 Vid. De anima, t. 1, d. 2, q. 3, pp. 184-185. 
su especie, pero dicen que esa forma no es un principio intelectivo, sino sensitivo y cogitativo por mediación de una facultad que se llama «cogitativa». Pero como además de esta actividad tenemos experiencia de que se da en el hombre otra de orden superior, que es la intelección, ponen en el hombre una cierta sustancia intelectual que denominan «entendimiento separado». No es una forma del hombre, sino que le presta simplemente su asistencia. Dicen que ese entendimiento es numéricamente el mismo en todos los hombres; sin embargo, no produce en todos ellos las mismas intelecciones por razón de la unión que tiene con los diversos actos de la fantasía. A esta unión se debe que tenga diversas intelecciones.» ${ }^{102}$ Suárez sostendrá que se trata de un grave error. Si reconocemos la existencia de múltiples almas y admitimos que ambos entendimientos son sus potencias, sería incongruente pensar que éstas no se multiplican. ${ }^{103}$

$\mathrm{Si}$ se sigue a Aristóteles, el intelecto agente es más perfecto que el posible. El primero parece prestar ayuda al segundo, lo que le hace superior. Suárez, sin embargo, opinará lo contrario. La acción del intelecto posible, calificada, ciertamente, de inteligencia, es nobilísima. Por él, nuestro espíritu es capaz de la visión divina, base de la felicidad humana, y se asimila a Dios y a los ángeles. Con todo lo que es, del intelecto agente no se saldrá de este tipo de actividad. Suárez lo define simplemente como un instrumento destinado a preparar las especies del intelecto posible y a suplir el defecto de los objetos materiales. ${ }^{104}$

****

En sus investigaciones sobre la naturaleza del entendimiento agente, opinamos que Suárez viene a ofrecer una síntesis de las tesis del Doctor Angélico y de las innovaciones introducidas por Guillermo de Ockham y sus seguidores. Santo Tomás insistirá, contra las interpretaciones alejandrinistas y averroístas de Aristóteles, que el intelecto agente no es una sustancia separada, sino algo perteneciente al alma. El Estagirita explicó el mecanismo del pensamiento a partir de la distinción de dos entendimientos: el posible, en potencia para recibir formas inteligibles, y el agente, análogo a la luz, presentado como causa eficiente o productora de dichas formas. Algunos de sus comentadores, entre los que se hallaba Alejandro de Afrodisia, consideraron que el entendimiento agente estaba separado, era inmortal y eterno. Tomás de Aquino sostuvo que, en toda alma humana individual, hallamos, como potencias propias, los entendimientos agente y posible. Al afirmar que el entendimiento y la voluntad sólo se diferenciaban nominalmente y que no eran más que maneras de manifestarse el alma racional humana, el Venerabilis Inceptor dejó claro que la discriminación entre intelecto agente y paciente obedecía también a esa diferenciación verbal. Lo que se tiene por dos intelectos no son más que actos distintos de nuestra alma. Contra los averroístas, Suárez, con Tomás de Aquino, dirá que el intelecto, con sus dos potencias, es numéricamente múltiple y no uno para todos los hombres. Ante la negación nominalista, el Eximio defenderá la existencia de los dos entendimientos, notificará su distinción real y definirá sus respectivas actividades. Será en la definición de estas actividades en donde se podrá percibir una cierta influencia de la metodología crítica ockhamista. En una visión global, primero Suárez observa las actividades del entendimiento respecto de läs de los sentidos; determinadas las primeras, pasará a distribuirlas entre ambos entendimientos según una definición muy concreta de sus facultades, las cuales avalarán su existencia real. Aquí llegamos al punto espinoso de su psicología: la limitación

102 Ibidem, d. 2, q. 4, pp. 253-255.

103 De anima, I. IV, c. 8, a. 8, p. 743:... sequitur primo intellectum agentem et possibilem non esse unum eumdemque in omnibus hominibus, sed multiplicari pro multiplicatione animarum [...]: nam multiplicata forma, multiplicantur consequenter ejus potentiae.

104 Ibidem, p. 744: Resolvendum tamen possibilem simpliciter esse nobiliorem. Primo, quia ejus actio, nimirum intellectio, nobilissima est, nec talis ulla prodit ab intellectu agente. Secundo per intellectum possibilem est noster animus capax divinae visionis, in qua beatitudo hominis consistit. Tertio intellectus agens non nisi ut instrumentum quoddam datum est praeparandis possibili speciebus. Quarto secundum intellectum possibilem maxime Deo et Angelis assimilatur. 
de la actividad del intelecto agente - -en cierta manera, una desmitificación de una potencia tradicionalmente contemplada como quasi-divina - a dos acciones sucesivas: iluminar y abstraer, y el aumento de interés gnoseológico del posible. La tópica superioridad del agente desaparece: llegará a decir incluso que el posible es absolutamente más perfecto si se tienen en cuenta sus funciones. ${ }^{105}$ Pero el interés del Eximio no es tanto la perfección o superioridad de uno o de otro, sino su real distinción en el proceso cognitivo. Suárez destaca que ambos intelectos se diferencian realmente, y se prueba por el hecho de realizar acciones totalmente diferentes: la agendi y la patiendi. ${ }^{106}$

Aunque Suárez se refiera a una misma alma que ve por la vista, que imagina por la imaginación y que entiende por el entendimiento, ${ }^{107}$ el paso a la reducción de Ockham, ciertamente, no se puede dar ni ontológica ni psicológicamente en el sistema suarista. Si se quiere realizar una teoría del entendimiento, parece imprescindible tener que fundamentar ónticamente sus potencias. Ahora bien, mantener las mismas notas distintivas de la filosofía tomista para hablar de ambos intelectos podría afectar también a la coherencia de la síntesis metafísica propuesta por Suárez. La función del entendimiento agente consiste, simplemente, en formar las especies intencionales. Si se le califica de luz, antes se habrá de contar con el significado de luz. Suárez busca siempre la significación más general y esto puede causar sorpresas y ver que lo exclusivo, en nuestro caso la atribución de poder lumínico sólo al intelecto agente, puede dejar de serlo: el posible también se puede ver como luz.

En cuanto a la concepción de los intelectos agente y posible, Suárez se mueve en la línea general de tradición tomista: hay un entendimiento que produce las especies, el agente, y otro que realiza la intelección de las mismas, el paciente. Según José $\mathrm{M}^{\mathrm{a}}$ Alejandro, las funciones fundamentales del intelecto agente, en la doctrina de la escolástica, se reducen a tres: (a) iluminar el fantasma; (b) hacer inteligible el objeto; y (c) abstraer la especie del fantasma. ${ }^{108} \mathrm{Com}$ paradas con las definiciones que de estas funciones ofrece el tomismo, como hace el P. Alejandro, advertimos una simplificación en las de Suárez no exenta de dificultad. ¿Qué aporta a esa teoría de la producción de especies en relación a las filosofías precedentes? El P. Alejandro cree que su posición se puede fijar en tres puntos: (1) el entendimiento agente exige una determinación del fantasma para la producción de la especie; (2) la determinación por parte del fantasma no se opera por ningún influjo del mismo fantasma, sino por una manifestación ejemplar que el fantasma ofrece al entendimiento agente; y (3) fuera de esta producción de las especies, el entendimiento agente no posee otra actividad. ${ }^{109}$ Los dos primeros remiten al gran problema aristotélico de la abstracción de la especie, es decir, a la tercera función fundamental del intelecto agente. Al hablar aquí de abstracción o de elevación de la representación material del fantasma a la representación espiritual, nos referimos simplemente a la producción por parte del entendimiento agente de una especie que representa espiritualmente el objeto representado en el fantasma. ${ }^{110}$ Clemente Fernández indica que, en esta producción del entendimiento agente, «la doctrina de Suárez no ofrece alguna particularidad digna de notarse sobre la enseñanza común en la escolástica:» ${ }^{111}$ No parece opinar lo mismo José $\mathrm{M}^{\mathrm{a}}$ Alejandro, quien resume muy bien la contestación dada sobre la cuestión por parte de Suárez al tomișmo: «sería pueril imaginar una especie espiritual encerrada en el fantasma y liberada de él por el entendimiento agente.» ${ }^{12} \mathrm{Al}$ Eximio le interesa más aclarar el sentido de la abstracción que expli-

105 Vid. De anima, 1. IV, c. 8, n. 11, p. 744. De anima, t. III, d. 9, q. 8, pp. 230-233.

106 Vid. ibílem, c. 8, n. 12, p. 744.

107 Cfr. De anima, t. II, d. 6, q. 2, p. 487.

108 José $\mathrm{M}^{\mathrm{a}}$ Alejandro, op. cit., p. 241.

109 Ibidem.

110 Vid. De anima, 1. IV, c. 2, n. 18, p. 721.

111 Clemente Fernández, op. cit., p. 77.

112 José $\mathrm{M}^{\mathrm{a}}$ Alejandro, op. cit., p. 241. 
car la labor del intelecto agente; cree que, haciendo lo primero, facilitará lo segundo. Pensar en una potencia activa que depura el fantasma para hacer emerger la esencia, la cual tendrá que ser informada al intelecto posible, es, en cierta manera, restar importancia al trabajo espiritual del alma.

En resumen, si algo queda claro en Suárez, es que el intelecto agente es una potencia espiritual no cognoscitiva, cuya acción se limita a una sucesión gnoseológica que va de la iluminación de la imagen a la producción de su especie.

Andrés Grau i Arau

Universitat Ramon Llull

Facultat de Filosofia

C/ Diputació, 231

08007 Barcelona

agrau2@pie-xtec-es. 